\title{
2 Non-verbal Predicates in Sumerian
}

\subsection{Introduction}

In Sumerian there exist two kinds of non-verbal predicates. In the more common type, the predicate contains a verbal copula. Non-verbal predicates of this type will be referred to as copular clauses throughout this work. The next section gives a descriptive overview of the copular clauses.

If the subject of the non-verbal predicate is in the 3rd ps. sg., then the non-verbal predicate may occur without a copula in certain contexts. This type of non-verbal predicate will be discussed in the last section of this chapter.

\subsection{Copular Clauses: the Most Important Characteristics}

The Sumerian copular clause (henceforth, CC) is an intransitive clause which consists of two main parts: a) the subject (henceforth, S), and b) a non-verbal predicate. The predicate itself consists of two parts: i) a structural unit functioning as the predicate complement (henceforth, PC) and ii) a copula (henceforth, COP).

The Sumerian COP is formed from the verb me "to be". It has two forms: the independent and the enclitic COP. The independent COP is a finite verb with at least one verbal prefix, while the enclitic COP is attached to the last word of the clause, without any prefix. As a rule, the PC is situated next to the COP; if the COP is enclitic, it cliticizes to the PC. Ex. (19) contains a 3rd ps. sg. enclitic COP cliticized to the last unit of the PC:

(19) En-metena 7 21-22 (RIME 1.9.5.7) (Lagash, 25th c.) (P222539)

\begin{tabular}{|c|c|c|c|}
\hline $\begin{array}{l}\text { ud-ba } \\
u d=b i=' a\end{array}$ & $\begin{array}{l}\text { du-du, } \\
{ }_{s}[\mathrm{dudu}=\varnothing]\end{array}$ & sanja & 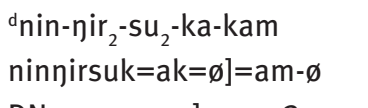 \\
\hline $\mathrm{day}=\mathrm{DEM}=\mathrm{L} 1$ & ${ }_{S}[\mathrm{PN}=\mathrm{ABS}]$ & ${ }_{P C}$ [official & $\mathrm{DN}=\mathrm{GEN}=\mathrm{ABS}]=\mathrm{COP}-3 \mathrm{SG} . \mathrm{S}$ \\
\hline
\end{tabular}

Like other stative verbs in Sumerian, the COP has only a preterit and no present-future form. Both the independent and the enclitic COPs are suffixed with the set of pronominal suffixes that are coreferential with the participant in the absolutive case in preterit tense verbal forms. In the 3rd ps. sg., the enclitic COP uses a special stem, 
/am/ instead of /me/. ${ }^{26}$ The final /e/ of the COP and the initial /e/ of the pronominal suffixes contracted to a single vowel, which may have been long.

Tab. 2.1: Forms of the copula

\begin{tabular}{|c|c|c|c|c|c|c|}
\hline & \multicolumn{3}{|l|}{ singular } & \multicolumn{3}{|l|}{ plural } \\
\hline & 1st & 2nd & 3rd & 1st & 2nd & 3rd \\
\hline $\begin{array}{l}\text { independent } \\
\text { enclitic }\end{array}$ & $\begin{array}{l}\text {-me-en } \\
=\text { me-en }\end{array}$ & $\begin{array}{l}\text {-me-en } \\
=\text { me-en }\end{array}$ & $\begin{array}{l}-\mathrm{me}-\varnothing \\
=a m-\varnothing\end{array}$ & $\begin{array}{l}\text {-me-enden } \\
=\text { me-enden }\end{array}$ & $\begin{array}{l}\text {-me-enzen } \\
=\text { me-enzen }\end{array}$ & $\begin{array}{l}\text {-me-eš } \\
=\text { me-eš }\end{array}$ \\
\hline
\end{tabular}

The $\mathrm{S}$ of a CC is in the absolutive case. The COP agrees in person and number with the $\mathrm{S}$. In some rare cases, when the relation between a possessor and the $\mathrm{S}$ is inalienable, then the COP may agree with the possessor of the $S$ instead. ${ }^{27}$ In ex. (20) below the COP agrees with the 2 nd ps. sg. possessor of the $\mathrm{S}$ in both clauses. ${ }^{28}$

(20) Iddin-Dagan D 30 (ETCSL 2.5.3.4)

igi-zu

huš-me-en

igi $=z u=\varnothing$

${ }_{P C}[$ huš- $\varnothing=\varnothing]=m e-e n$

face $=2 \mathrm{SG} . \mathrm{POSS}=\mathrm{ABS} \quad{ }_{\mathrm{PC}}[$ awesome-TL=ABS $]=$ COP-2SG.S

za-pa-' ${ }^{\top} \eta_{2}-$ zu' $^{\top} \quad$ 'mah?'-me-en ${ }^{\top}$

zapan $=z u=\varnothing \quad$ PC $[$ mah- $\varnothing=\varnothing]=$ me-en

cry $=2 \mathrm{SG} . \mathrm{POSS}=\mathrm{ABS} \quad \mathrm{PC}_{\mathrm{PC}}[\mathrm{majestic}-\mathrm{TL}=\mathrm{ABS}]=$ COP-2SG.S

"Your face is awesome, your cry is majestic."

The S of a CC may be expressed in three ways: i) both as an overt lexical NP and by an unaccented pronominal suffix on the COP; ii) solely by the unaccented pronominal suffix on the COP; or iii) both as an independent pronoun and by an unaccented pronominal suffix on the COP.

The $\mathrm{PC}$ is as a rule in the absolutive case. Less frequently it may be in the genitive, as in exx. (21), (22) and (23); ablative (expressing an instrumental meaning), as in ex. (24); or equative, as in ex. (25) below:

26 See Edzard (2003, p. 83) and Jagersma (2010, p. 682) on the origin of the stem /am/.

27 For the phenomenon of external possession in Sumerian, see Zólyomi (2005).

28 See Zólyomi (2005, p. 184, n. 20), and for a different analysis, see Jagersma (2010, p. 710). 
(21) En-ana-tum I 2 8:5 (RIME1.9.4.2) (Lagash, 24th c.)

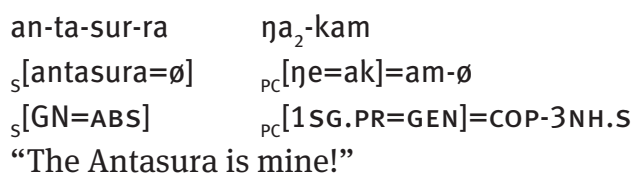

(22) TCS 1, 177 rev. 2 (?, 21st c.) (P145700)

$\mathrm{gu}_{2}$-na-kam

gu=ani=ak=am $\varnothing$

${ }_{\mathrm{PC}}[$ neck=3SG.POSS $=\mathrm{GEN}]=$ COP- $3 \mathrm{NH} . \mathrm{S}$

"It is of his neck." = "It is his responsibility."

(23) Nungal A 75 (ETCSL 4.28.1)
arhuš šag $_{4}-$ ne-ša ${ }_{4} \quad \eta a_{2}$-a-kam
${ }_{s}[$ arhuš šagneša $=\varnothing] \quad{ }_{P C}[$ [ne $=a k]=a m-\emptyset$
${ }_{S}[$ mercy compassion=ABS $] \quad{ }_{\mathrm{PC}}[1 \mathrm{SG} \cdot \mathrm{PR}=\mathrm{GEN}]=\mathrm{COP}-3 \mathrm{NH} . \mathrm{S}$
"Mercy and compassion are mine.

(24) NG 2148 (Umma, 21st c.) (P131761)

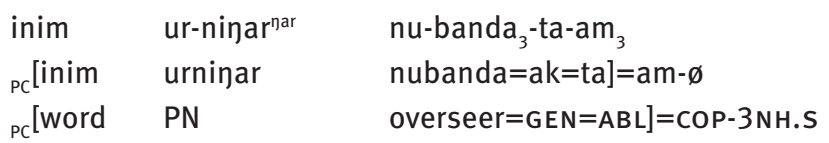

"This was with the permission of Urnigar, the overseer."

(25) TCS 1, 327 3-4 (Lagash, 21st c.) (P111288)

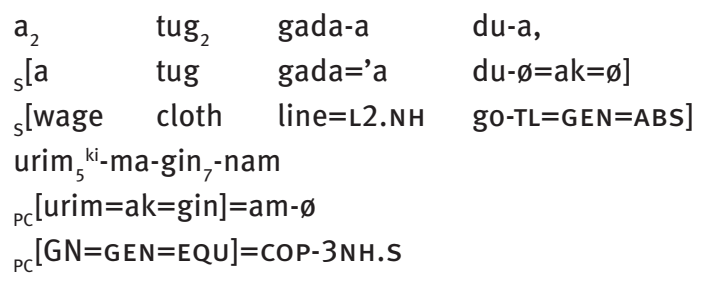

"The wages for 'walking' on cloth and line are as those of Urim."

The independent and the enclitic COP occur in complementary distribution. The independent form of the COP is used i) when the meaning of the predicate requires the use of a verbal prefix other than the finite-marker prefix (this verbal prefix is a modal prefix in the first verbal slot in ex. [26], while it is the coordinator prefix in the third verbal slot in ex. [27]); ii) in subordinate CCs, including complement clauses such as ex. (28) and relative clauses such as ex. (29). A special type of complement clause is represented by ex. (30), in which the subordinate CC functions as the PC of another CC; see section 6.2 below on this construction. In morphosyntactic environments other than i) and ii), the enclitic COP is used. The enclitic COP thus occurs in place of a non-subordinate 
independent COP whose prefix-chain consists exclusively of a finite-marker prefix. It may have come into being through the syncopation of the finite-marker prefix /i/-. As is often the case, the older form was retained in subordinate contexts. ${ }^{29}$

(26) Lugalbanda 106 (ETCSL 1.8.2.2)

dinir he -me-en

${ }_{P C}[$ dinir $=\varnothing] \quad{ }_{S 1}$ ha- $_{S 2}{ }^{i}{ }_{-}{ }_{S 12}$ me- $_{S 14}$ en

${ }_{\mathrm{PC}}[\mathrm{god}=\mathrm{ABS}] \quad$ MOD-FIN-COP-2SG.S

"if you are a god, ...."

(27) Shulgi C 9 (ETCSL 2.4.2.03)

\begin{tabular}{|c|c|c|}
\hline $\begin{array}{l}\text { nin }_{2} \text {-erim } \\
\text { PC's Poss } \\
\text { Pninerim }=\text { ak] }\end{array}$ & $\begin{array}{l}\text { usan }_{3} \\
\text { PC [usan }\end{array}$ & $\begin{array}{l}\text { bar-uš-bi } \\
\text { baruš=bi=ø] }\end{array}$ \\
\hline P's Poss $[$ evil=GEN] & ${ }_{\mathrm{PC}}^{[\text {scourge }}$ & stick $=3 \mathrm{NH} \cdot \mathrm{POSS}=\mathrm{ABS}$ \\
\hline & in-ga-me-en, & \\
\hline${ }_{5}[n e=\varnothing]$ & ${ }_{\mathrm{s} 2} \mathrm{i}_{\mathrm{s} 3} \mathrm{nga}_{\mathrm{s} 12} \mathrm{~m}$ & e- ${ }_{s 14}$ en \\
\hline ABS] & FIN-COOR-CO & G.S \\
\hline
\end{tabular}

"As for all evil, their scourge and stick are also me."

(28) NG 21217 (Umma, 21st c.) (P142272)

$\operatorname{arad}_{2} \quad \mathrm{~d}_{\mathrm{S} a r a} \mathrm{i}_{3}-\mathrm{me}-\mathrm{a}$

${ }_{\mathrm{PC}}[\mathrm{arad} \quad$ šara $\left.=\mathrm{ak}=\varnothing] \quad{ }_{\mathrm{S} 2}^{\mathrm{i}} \mathrm{s}_{\mathrm{S} 12} \mathrm{me}_{\mathrm{S14}}{ }^{\varnothing-}{ }_{\mathrm{S} 15}{ }^{\prime} \mathrm{a}\right]=\mathrm{ak}$

${ }_{\mathrm{PC}}$ [slave $\left.\mathrm{GN}=\mathrm{GEN}=\mathrm{ABS}\right] \quad \mathrm{FIN}$-COP-3SG.S-SUB $=\mathrm{GEN}$

"(Lugalazida is to take the assertory oath) that he (= Lugalitida) is a slave of the god Shara.”

(29) ASJ 4, p. 141, no. 6 obv. 2 (Drehem, 21st c.) (P102167)

ud

ud ${ }_{\mathrm{PC}}[$ tur-'a=ø]

day ${ }_{\mathrm{PC}}$ [ill-PT=ABS]

"When he was ill."

$$
\mathrm{i}_{3}-\mathrm{me}-\mathrm{a}
$$

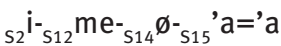

FIN-COP-3SG.S-SUB=L1

(30) NG 70 9' (Lagash, 21st c.) (P111448)

$\mathrm{lu}_{2}{ }^{-\mathrm{d}} \mathrm{li}_{8}-\mathrm{si}_{4} \quad l \mathrm{u}_{2}$-gi-- ${ }^{\mathrm{T}}$ na'-ab-tum-bi $\mathrm{i}_{3}-\mathrm{me}^{-a m_{3}}$

${ }_{\mathrm{PC}}\left[l_{S}[\right.$ lulisi $=\varnothing] \quad{ }_{\mathrm{PC}}[$ luginabtum $=\mathrm{bi}=\varnothing]$ $\left.{ }_{S 2}{ }^{i}-_{S 12}{ }^{m e-}{ }_{S 14} \emptyset{ }_{S 15}, a=\varnothing\right]=a m-\varnothing$

${ }_{\mathrm{PC}}\left[\mathrm{C}_{\mathrm{S}}[\mathrm{PN}=\mathrm{ABS}] \quad{ }_{\mathrm{PC}}\right.$ [guarantor=Poss. $\left.3 \mathrm{NH}=\mathrm{ABS}\right]$

FIN-COP-3SG.S-SUB=ABS] $=$ COP-3NH.S

"It was (the case) that Lu-Lisi was its guarantor."

29 See Bybee et al. (1994, pp. 230-231) about the conservatism of subordinate forms. Cf. also Heine (2003, p. 586) who states: "Not uncommonly, lexical properties are lost in main clauses but may survive in subordinate clauses”. 
Non-verbal predicates may be negated in two ways: i) A CC with a 3rd ps. sg. S and an enclitic COP is negated solely with the negative particle / nu/, and the negative clause contains no COP; ii) if the $\mathrm{S}$ is not in the 3rd ps. sg. and/or the COP is not enclitic, then the clause is negated with an independent COP prefixed with the negative prefix /nu/- (cf. ex. [65] and ex. [124] below). Non-verbal predicates negated with just the negative particle / $\mathbf{n u /}$ will be discussed in the next subsection. ${ }^{30}$

Non-verbal predicates may be used to express a range of semantic relations. In English, for example, the same verb, be, is used to express identity, attribution, possession, benefaction and location (cf. Dixon, 2010, pp. 159-162). In Sumerian only the first four of the semantic relations listed by Dixon are expressed with the copular verb me "to be", ${ }^{31}$ with location being expressed through a different lexical item, the verb nal "to exist somewhere". ${ }^{32}$ In ex. (31), for example, the relative clause in P2, set in bold and italic in the translation, uses the verb nal for describing the location of the tablets.

(31) MVN 3, 363 rev. 4-5 (Drehem, 21st c.) (P113923)

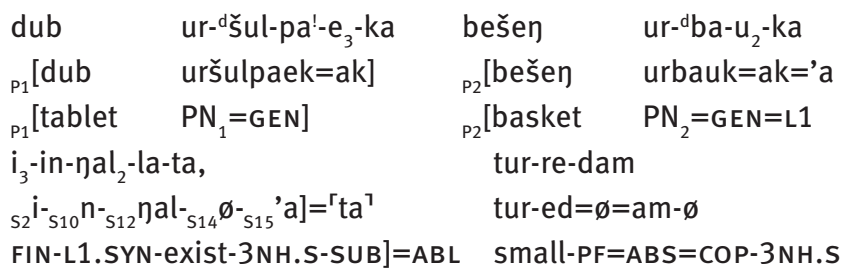

"These (various animals) are to be subtracted from the tablet of Ur-Shulpae that is in the basket of Ur-Bau."

The only apparent exception to this generalization I am aware of is ex. (32) below, which is usually translated as expressing location: "(The elders of the city declared) that the burial place of the city's chief lamentation priest was in the garden". ${ }^{33}$ This interpretation, however, is not the only grammatically possible one. One may also take the word kimah "grave" alone as the S of the CC, in which case the CC may be interpreted as expressing possession. Given the generalization made in the previous paragraph, this second interpretation appears to be preferable.

30 In texts from the 2nd millennium BC and later the negative particle / $\mathbf{n u} /$ is sporadically attested as the verbal base of a finite verb, preceded by an /i/- finite marker; see Thomsen (1984, p. 192, §164). 31 For a non-verbal predicate expressing benefaction cf. ex. (74) below.

32 Cf. also Gragg (1968, p. 102), who concludes in his study on the Sumerian copula: "Thus, apart from some marginal and doubtful cases, me in Sumerian is limited to the function of simple predication, and does not, as opposed to 'be' in most Indo-European languages, extend over into the semantic field 'exist”'.

33 Cf. Falkenstein (1956b, pp. 166-168), Jagersma (2010, p. 602, ex. 81). 
(32) NG 101 13-14 (Lagash, 21st c.) (P111445)

\begin{tabular}{|c|c|c|c|c|}
\hline$i_{6}-a$ & $\begin{array}{l}\text { ki-mah, } \\
{ }_{\mathrm{s}}[\mathrm{kimah}=\varnothing]\end{array}$ & $\begin{array}{l}\text { gala-mah } \\
\text { C } \text { galamah } \\
\text { [priest }\end{array}$ & $\begin{array}{l}\text { iri-ka } \\
\text { iri=ak=ak] } \\
\text { city=GEN=GEN] }\end{array}$ & $\begin{array}{l}\mathrm{i}_{3}-\mathrm{me}-\mathrm{a} \\
{ }_{\mathrm{s} 3} \mathrm{i}_{\mathrm{s} 12} \mathrm{me}_{\mathrm{s} 14} \emptyset-{ }_{\mathrm{s} 14}{ }^{\prime} \mathrm{a}={ }^{\prime} \mathrm{a}\end{array}$ \\
\hline
\end{tabular}
"(The elders of the city declared) that in the garden the burial place belonged to the city's chief lamentation priest.”

\subsection{Copula Dropping: Non-verbal Predicates without a Copula}

If the $S$ is in the 3rd ps. sg., then the non-verbal predicate may occur without a COP in certain grammatical environments, a phenomenon called copula dropping in linguistics. ${ }^{34}$ There exists four grammatical environments in which the non-verbal predicate is attested to omit the COP: i) CCs functioning as proper names (names of persons, statues etc.) in which the $S$ is an overt lexical noun; ii) seal inscriptions; iii) negated counterparts of CCs in which the $\mathrm{S}$ is in the 3rd ps. sg. and the COP is enclitic; iv) interrogative clauses.

\subsubsection{Copular Clauses Functioning as Proper Names}

In proper names consisting of a non-verbal predicate, the COP may be omitted if the $S$ of the clause is an overt lexical noun, as in exx. (33), (34), (35), and (36). If the $S$ is not an overt lexical noun, then the COP is present, as shown by exx. (37), (38) and (39). In ex. (39) the presence of the COP is also triggered by the person of the $\mathrm{S}$, as it is 2nd ps. sg.; i.e. different from $3 r d$ ps. sg.

Exx. (33), (34), (37), (38) and (39) are personal names; ex. (35) is the name of a statue; and ex. (36) is the name of an unknown object that could not carry an inscription; its name was inscribed on a small clay olive that may have been attached to this object.

(33) UET 2, 338 rev. 2:2 (Ur, 28th c.) (P005925)

ama-neštin

${ }_{S}[\text { ama }=\varnothing]_{\mathrm{PC}}[$ [neštin $=\varnothing]$

${ }_{S}[\text { mother }=A B S]_{P C}[$ wine $=A B S]$

"The-mother-is-wine"

34 See Jagersma (2010. pp. 715-718). Jagersma was the first to drawn attention to this type of nonverbal predicate in Sumerology. On the phenomenon of copula dropping see Pustet (2003, pp. 34-39). 
(34) Amar-Suena 201 (RIME 3/2.1.3.20) (Ur, 21st. c) (P200450)

nin-he - -du

${ }_{S}[\text { nin }=\varnothing]_{\mathrm{PC}}[$ hedu $=\varnothing]$

${ }_{S}[\text { lady }=\text { ABS }]_{P C}$ [ornament $=$ ABS $]$

"The-lady-is-an-ornament"

(35) Amar-Suena 10 1:11 (RIME 3/2.1.3.10) (Ur?, 21st c.)

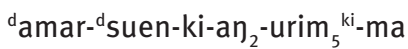

${ }_{S}[\text { amarsuenak }=\varnothing]_{P C}[k i=\varnothing$ an- $\varnothing$ urim $=a k=\varnothing]$

${ }_{5}[\mathrm{PN}=\mathrm{ABS}]_{\mathrm{PC}}[\mathrm{place}=\mathrm{ABS}$ measure $-\mathrm{TL} \mathrm{GN}=\mathrm{GEN}=\mathrm{ABS}]$

"(The name of this statue is) 'Amar-Suena-is-the-beloved-of-Urim'."

(36) Iri-kagina 14h (Lagash, 24th c.) (P222644)

dba-u ${ }_{2}$-ama-iri-ka-gi-na-ka,

${ }_{S}[\mathrm{bau}=\varnothing]_{\mathrm{PC}}[$ ama irikaginak $=\mathrm{ak}=\varnothing]$

${ }_{S}[\mathrm{DN}=\mathrm{ABS}]_{\mathrm{PC}}[$ mother $\mathrm{RN}=\mathrm{GEN}=\mathrm{ABS}]$

"(As for this object,) 'Bau-is-the-mother-of-Iri-kagina' (is its name).”

(37) Nam-mahni 119 (RIME 3/1.1.12.11) (Lagash, 22nd c.) (P234704)

dutu-kam

${ }_{\text {PC }}[$ utu $=a k]=a m-\varnothing$

${ }_{P C}[\mathrm{DN}=\mathrm{GEN}]=$ COP-3SG.S

"He-is-Utu's"

(38) Inana and Gudam Segment A 1 (ETCSL 1.3.4)

gud-dam

${ }_{\mathrm{PC}}[\mathrm{gud}=\varnothing]=\mathrm{am}-\varnothing$

${ }_{\mathrm{PC}}[\mathrm{bull}=\mathrm{ABS}]=$ COP-3SG.S

"He-is-a-bull"

(39) VS 25, 69 10:13 (Lagash, 24th c.) (P020275)

ama-nu $\mathrm{u}_{10}$-me

${ }_{\mathrm{PC}}[\mathrm{ama}=\eta \mathrm{u}=\emptyset]=$ me-en

${ }_{\mathrm{PC}}[$ mother $=1 \mathrm{SG} . \mathrm{POSS}=\mathrm{ABS}]=\mathrm{COP}-2 \mathrm{SG} . \mathrm{S}$

"You-are-my-mother"

\subsubsection{Seal Inscriptions}

In seal inscriptions ending with the "your slave" formula that functions as the predicate, the COP never occurs, as in ex. (40) below. 
(40) Shulgi 86 (RIME 3/2.1.2.86) (?, 21st c.) (P226941)

\begin{tabular}{|c|c|c|c|c|}
\hline $\begin{array}{l}\text { ba-qar -tum, } \\
\text { baqartum }\end{array}$ & $\begin{array}{l}\text { dumu-munus } \\
\text { dumumunus }\end{array}$ & $\begin{array}{l}\text { lugal, } \\
\text { lugal=ak=ø }\end{array}$ & $\begin{array}{l}\text { dšul-gi-i } i_{3}-l i_{2}, \\
{ }_{5}[\text { šulgiili=ø] }\end{array}$ & $\begin{array}{l}\operatorname{arad}_{2}-z u \\
{ }_{\mathrm{PC}}[\operatorname{arad}=z u=\varnothing]\end{array}$ \\
\hline & daughter & king $=\mathrm{GEN}=\mathrm{ABS}$ & ${ }_{s}\left[\mathrm{PN}_{2}=\mathrm{ABS}\right]$ & ${ }_{\mathrm{PC}}[\mathrm{slave}=2 \mathrm{sG} \cdot \mathrm{POSS}=\mathrm{ABS}]$ \\
\hline
\end{tabular}

"Baqartum, the king's daughter: Shulgi-ili is your servant!"

\subsubsection{Negated Copular Clauses}

A CC with a 3rd ps. sg. S and an enclitic COP is negated solely with the negative particle /nu/, and the negative clause contains no COP. ${ }^{35}$ An instructive example is (41) below. In this example the first clause is negated with the particle /nu/, while the second is negated with an independent COP prefixed with the negative prefix /nu/-.

(41) Gudea Statue B 7:49-50 (Lagash, 22nd. c.) (P232275)

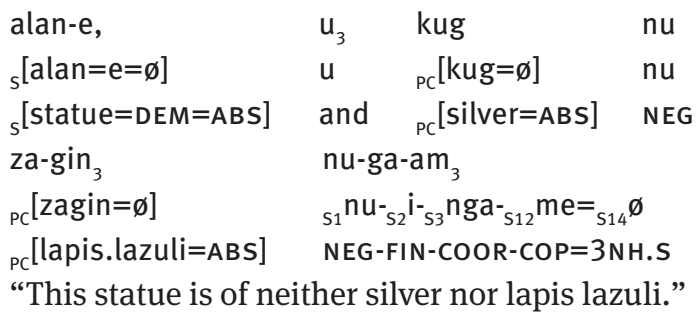

The affirmative equivalent of the first clause would contain the 3rd ps. sg. form of the enclitic COP ( ${ }^{\star} \mathbf{k u g}=\boldsymbol{\emptyset}=\mathbf{a m}-\boldsymbol{\emptyset}$ : silver $=\mathrm{ABS}=\mathrm{COP}-3 \mathrm{NH} . \mathrm{S}$ ), while the affirmative equivalent of the second clause would contain an independent COP because of the presence of a coordinator prefix in S3 $\left({ }_{\mathrm{S} 2} \mathbf{i}-{ }_{\mathrm{S} 3} \mathbf{n g a}_{\mathrm{S}_{2}} \mathbf{m e}_{\mathrm{S14}} \boldsymbol{\emptyset}\right.$ : FIN-COOR=COP-3NH.S). The difference in the way the two clauses are negated in ex. (41) is conditioned thus by the form of the COP in the corresponding affirmative clauses. Exx. (42), (43) and (44) below are further examples of negated non-verbal predicates without a COP.

(42) E-ana-tum 1 rev. 10:23-25 (RIME1.9.3.1) (Lagash, 24th. c.)

\begin{tabular}{|c|c|c|c|}
\hline na-ru $-\mathrm{a}$ & mu-bi, & $\mathrm{lu}_{2}-\mathrm{a}$ & nu \\
\hline s's poss $[$ narua $=a k]$ & ${ }_{s}[\mathrm{mu}=\mathrm{bi}=\varnothing]$ & ${ }_{\mathrm{PC}}[\mathrm{lu}=\mathrm{ak}]$ & hu \\
\hline s's poss [stele=GEN] & ${ }_{s}[$ name $=3 \mathrm{NH}$. POSS $=A B S]$ & ${ }_{\mathrm{PC}}[$ person=GEN] & \\
\hline
\end{tabular}

35 Cf. Attinger (1993, p. 312, §206): “La contrepartie negative de -am 3 est -nu.” Note that this statement is not quite accurate. The morpheme / nu/ is not a negative copula. It is the morpheme that expresses negation in a clause without a COP. 
(43) Shulgi B 55 (= 80 = 117 = 153) (ETCSL 2.4.2.02)

\begin{tabular}{|c|c|c|c|c|}
\hline a-na-nu 10 & $\operatorname{nin}_{2}$ & ka-ge & dib-ba & $\mathrm{nu}$ \\
\hline${ }_{s}[\mathrm{ana}=\eta \mathrm{u}=\varnothing]$ & ${ }_{\mathrm{PC}}^{[\mathrm{nin}}$ & $\mathrm{kag}=\mathrm{e}$ & dib-’a=ø] & nu \\
\hline${ }_{S}[$ what $=1 \mathrm{sG} \cdot \mathrm{POSS}=\mathrm{ABS}]$ & ${ }_{P C}$ [thing & mouth $=$ L3.NH & surpass-PT=ABS] & NEG \\
\hline
\end{tabular}

(44) The Lament for Urim and Sumer A95 (ETCSL 2.2.3)

$\begin{array}{ll}\text { dam- } \eta u_{10} & n u \\ { }_{\mathrm{PC}}[\mathrm{dam}=\eta \mathrm{n}=\varnothing] & \mathrm{nu} \\ { }_{\mathrm{PC}}[\text { wife=1SG.POSS=ABS }] & \text { NEG }\end{array}$

“(The father turned away from his wife saying:) 'She is not my wife!’”

\subsubsection{Interrogative Clauses}

If the $S$ of an interrogative clause is in the 3rd ps. sg., then the COP may be dropped. In exx. (45)-(47) the sentence initial interrogative pronoun is accompanied with a COP. The structure and function of these forms will be discussed in details in subsection 5.3.5 below.

In ex. (45) the first clause is interrogative, while the second one is declarative; the $\mathrm{S}$ of of both clauses is in 3rd ps. sg. In the first clause of (45) the COP after the PC is omitted, while in the second one the PC is followed by the COP. The absence of the COP in the first clause of ex. (45) is thus conditioned by the clause type.

(45) Enlil and Nam-zid-tara 23-24 (ETCSL 5.7.1)

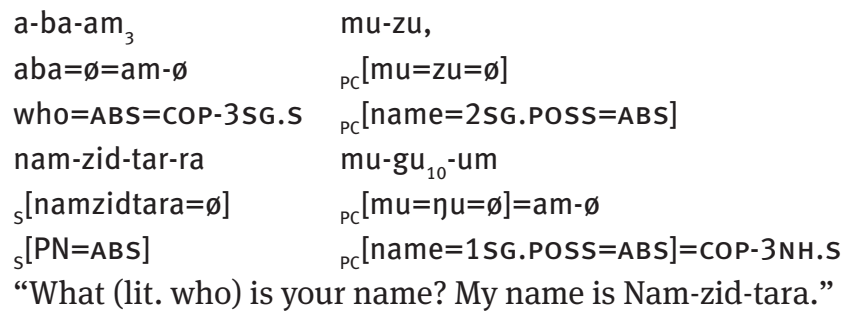

Exx. (46) and (47) are both interrogative clauses. In ex. (46) the $S$ of the clause is in the 3rd ps. sg., while in ex. (47) it is in the 2nd ps. sg. In ex. (46) no COP occurs after the $\mathrm{S}$, while in ex. (47) the $\mathrm{S}$ is followed by a COP. The presence of the COP in in these examples is conditioned by the person and number of the $\mathrm{S}$.

(46) Enki and Ninhursaga 201 (ETCSL 1.1.1)

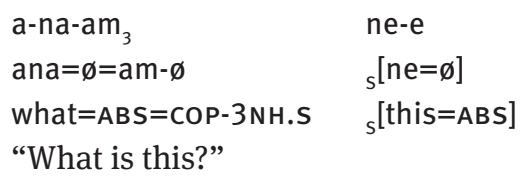


(47) Enlil and Nam-zid-tara 10-11 (ETCSL 5.7.1)

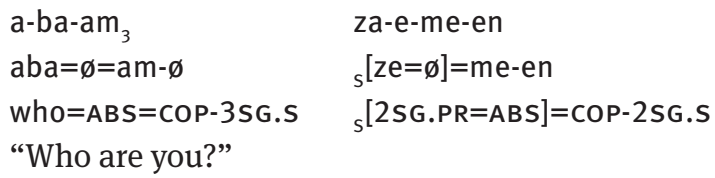

The condition on copula dropping may be overruled by prosodic factors. In ex. (48) below the S is in 3rd ps. sg., yet the COP is not dropped. The presence of the COP is the consequence of the prosodic prominence that the interrogative pronoun next to the COP carries. For a justification of this description, see subsection 5.3 .5 below.

(48) The three ox-drivers form Adab 15 (ETCSL 5.6.5)

amar-e a-ba-kam

${ }_{s}[\mathrm{amar}=\mathrm{e}=\varnothing]$ ${ }_{\mathrm{PC}}[\mathrm{aba}=\mathrm{ak}=\mathrm{am}-\varnothing]$

${ }_{5}$ [calf $=$ DEM $=$ ABS $] \quad{ }_{\mathrm{PC}}[\mathrm{WhO}=\mathrm{GEN}=$ COP-3SG.S $]$

"Whom does this calf belong to?" 